\title{
Relation between Soil Moisture and Occurrence of Dust Storms in Central Inner Mongolia, China
}

\author{
Ning $\mathrm{LI}^{*}$, Wei GU*1, Zixuan DU* and Seiji. HAYAKAWA ${ }^{* *}$ \\ "The Key Lab of Environmental Change and Natural Disaster, Ministry of Education of China, College of \\ Resources Science and Technology, Beijing Normal University, Beijing 100875, China \\ "Department of Biological and Environmental Sciences, Faculty of Agriculture, Yamaguchi University \\ Yamaguchi, 753-8515 Japan
}

\begin{abstract}
To study the influence of soil moisture on dust storms, the variety of daily mean soil moisture, daily mean wind speed and their integrative contributions are analyzed in the paper based on hourly soil moisture data observed from April 2001 to June 2003 and recorded meteorological data in central Inner Mongolia, China. The rationality of the statistic results were discussed, from which some interesting results can be drawn as follows: 1) The minimum value of daily mean wind speed during the dust storms is $3.5 \mathrm{~m} / \mathrm{s}$, and a dust storm would certainly occur when the wind speed exceeds $8 \mathrm{~m} / \mathrm{s}$ in this area. 2) In $18.4 \%$ of the whole data, when dust storms occurred, and in $81.6 \%$ of the whole data when no-dust storm occurred when the wind speed was above $3.5 \mathrm{~m} / \mathrm{s}$. This indicated that the dynamic factor of daily mean wind speed is not the most important influential factors for occurrence of dust storms. 3) Considering the soil moisture and wind speed only, when an inverse relation between daily mean soil moisture and daily mean wind speed comes into existence, dust storms would occurred $(r=-0.674)$. Otherwise, dust storms would not occur. The result indicates that formation and development of dust storms is an integrative result of soil moisture and wind speed. Continuous data of soil moisture would be an effective index to research dust storm for showing the humid status of soil directly and for scaling the status of vegetation cover indirectly.
\end{abstract}

Key words: Contribution, Dust storm, Inner Mongolia, Soil moisture, Wind speed

\section{Introduction}

The occurrence of dust storms is caused by special conditions in the weather and on the earth's surface. In Inner Mongolia, though dust storms occur frequently in spring, the numbers of days of dust storm emission are less than gale days according to statistics. This indicates that the formation of dust storms and their duration in Inner Mongolia are not correlative to gale weather only, but are influenced by integrative factors such as precipitation, temperature, vegetable coverage and gale weather. Dust storm activity mainly needs "sand startup" conditions in both the earth's surface and gales, and depends on the reciprocity action of physical medium with different density between the air and earth's surface. The actual study on dust storms focus mostly on the characteristics of dynamic climate, case analysis of the weather, vegetation coverage of the earth's surface, numerical value simulation and analysis of aerosol. The study of the earth's surface factors such as topography and physiognomy, sediment in earth's surface and the study of dust storms, specially focus on the relation between soil moisture and the emission of dust storm, focus on soil moisture how to effect the occurrence and development of dust storm is scarce. Through studies on the mechanisms of sand startup, degradation of grassplots, Vis doing, these studies are all separated in the field of topography and ecology, regional distribution of dust storms, and climate background of dust storms. Seeing the study of history and development of the relationship between dust storm activity and soil moisture, the data shortage of soil moisture corresponding to the period of dust storm is a key problem. This paper toward to study soil moisture that shows level of wetness of earth surface and mean wind speed that shows dynamic factor how to effect dust storm activity by means of statistics on their climate characteristics, and understand the significance of soil moisture to dust storm emission using hourly data. The results might supports scientific evidence for the establishment of countermeasures to prevent dust storms through quantitative analysis.

\section{Observations and Analytical Procedure}

\subsection{Study area}

Based on statistics, there are two major paths of dust storms in effect on Beijing from Inner Mongolia. One is the northern path which transits from Erlianhaote $\rightarrow$ Sunitezuoqi $\rightarrow$ Zhangjiakou $\rightarrow$ Beijing. The other is the north-west-north path which transit and from 
Table 1 Natural environment characteristics of observational station.

\begin{tabular}{ccccccc}
\hline Station & Soil Type & $\begin{array}{c}\text { Vegetation } \\
\text { Type }\end{array}$ & Climate Type & $\begin{array}{c}\text { Annual } \\
\text { Gale Days }\end{array}$ & $\begin{array}{c}\text { Annual } \\
\text { Precipitation } \\
\text { (mm) }\end{array}$ & $\begin{array}{c}\text { Annual Dust } \\
\text { Storm Days }\end{array}$ \\
\hline Wuhaishi & Gray-desert & Desert & Drought \& Warm & 32.0 & 168.5 & 22.7 \\
Wulaterzhongqi & Chestnut-calcium & Steppe & Drought \& Cold & 53.3 & 209.1 & 8.0 \\
Erlianhaote & Brown-calcium & Steppe & $\begin{array}{c}\text { Extreme } \\
\text { Drought \& Cool }\end{array}$ & 71.8 & 142.2 & 9.5 \\
\hline
\end{tabular}

Alashan $\rightarrow$ Wuhai $\rightarrow$ Zhunge'erqi $\rightarrow$ Beijing (Fan, et $a l, 2002$ ). To grasp the relation between dust storms soil moisture in the area, soil moisture is observed and analyzed from three locations on the two paths; Erlianhaote, Wulatezhongqi and Wuhaishi.

Erlianhaote, Wulatezhongqi and Wuhaishi are located in the central part of Inner Mongolia, and the climate falls within arid and very arid. They continuously suffer from serious drought, less precipitation and frequent gales. The maximum number of days that gales occurred was 10 days, and the minimum value was 5 days. The precipitation in spring was only $15 \%$ of that of the whole year. Gales occurring in spring accounted for $60-80 \%$ of the whole year. The wetness coefficient was $0.02-0.03$ from March to May. With the strong evaporation and shortage of soil moisture, poor vegetation coverage and serious desertification, the vulnerable natural and ecosystem, and earth surface in the area provide good conditions for the occurrence of dust storms. The characteristics of the natural environment in these locations are shown as Table 1.

\subsection{Data resources}

The observation instruments, ADR soil moisture (UIZ-SM-2X), were made in Japan, and were set up in meteorological stations each location above. The measured depth of the soil moisture was $0-10 \mathrm{~cm}$, and the measurement interval was selected as 1 hour. The soil moisture data was obtained from April 2001 to June 2003, and was the percentage of contained water by volume. Namely, soil moisture $=[$ containing water volume in soil $\left.\left(\mathrm{m}^{3}\right)\right] /$ soil whole volume $\left.\left(\mathrm{m}^{3}\right)\right] \times 100 \%$. The wind speed data come from weather observation station in the three locations above.

\section{Contribution of Soil Moisture to Dust Storms}

\subsection{Minimum wind speed of occurrence of dust} storms

Gale weather refers to a dynamic factor that causes dust storms. A wind tunnel experiment indicates that sand grains at different surfaces have different sand startup wind speeds. The more thick the dust and clay, the higher the sand startup wind speed will be. The amount of sand blown up by different wind speeds has obvious differences. It increases with respect to increasing wind speed. On the other hand, dust storm emission is also due to the relation of the relative wetness of the earth's surface under the same sand startup wind speed and surface grain conditions.

Figure 1 indicates the change of daily mean wind speed observed from April 2001 to June 2003. The solid points show daily mean wind speed, and the empty points show daily mean wind speed during the periods of dust storm. From Fig. 1, daily mean wind speed is increasing with exponentially at a significant level of $p<0.001(r=0.9201)$, and the minimum daily mean wind speed during the period of dust storm occurring was $V=3.5 \mathrm{~m} / \mathrm{s}$. Namely, $V=3.5 \mathrm{~m} / \mathrm{s}$ daily mean wind speed is the critical value for the occurrence of dust storms in the study area. Further, with respect to the exponential increase of daily mean wind speed, the frequency of dust storms also increased. The solid points and empty points almost superpose when daily mean wind speed is more than $8.0 \mathrm{~m} / \mathrm{s}$. This indicates that if daily mean wind speed passed above $8.0 \mathrm{~m} / \mathrm{s}$, a dust storm must occur in the study area.

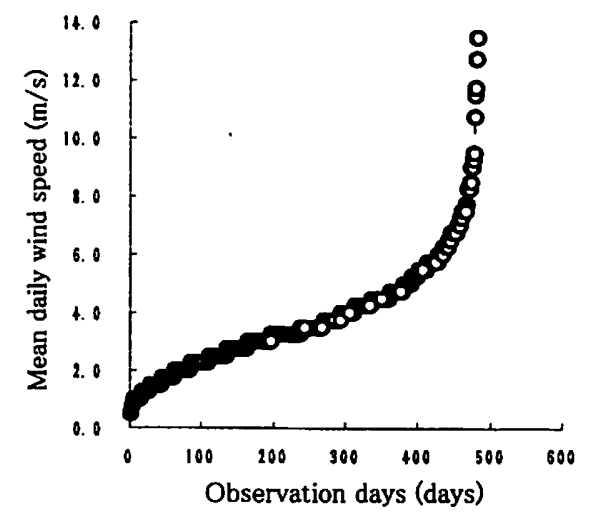

Fig. 1. Daily mean wind speed and its corresponding wind speed during the period occurring dust storms. The solid points show daily mean wind speed, and empty points show daily mean wind speed during the dust storm period.

\subsection{Classification of dust storms}


The occurrence of dust storms is caused by the influence of border level stability and the wetness of earth's surface. When analyzing the data of daily mean wind speed above $3.5 \mathrm{~m} / \mathrm{s}$, in $18.4 \%$ of the whole data dust storm occurred, and $81.6 \%$ of it there was nooccurrence of dust storm. Namely, most days had no dust storm emission even though the daily mean wind speed had exceeded the critical value of dust storms occurring. Dust should be the integrative result of wind speed and earth surface conditions. To consider the integrative influence of wind speed and soil moisture, two types was separated for dust storm and no-dust storm with critical value $V>3.5 \mathrm{~m} / \mathrm{s}$. The difference of soil moisture contributed to dust storm in the two types are analyzed.

\subsection{Influence of soil moisture on dust storm}

Studies on the earth's surface and temporal change regulation indicated a negative relation between vegetable coverage and the number of days that dust storms occurred (Gu, et al., 2002), and indicated that vegetables coverage is an important index to scale storms and the earth's surface type of topography and sandlot was higher than of that of the other types (Bai, et al., 2003). The relationship between dust storms and the earth's surface type of topography and sandlot was higher than of that of other types (Bai, et al., 2003). The land use of the earth's surface and vegetables coverage in areas passed by dust storms directly affect the forming and intensity of dust storms. On the other hand, soil moisture is an important factor to prevent wind power moving soil grain from one place to other place. The less moisture in soil, the greater dryness. If the soil grain becomes small enough, the dust is blown up easily in to sky by gales. Soil moisture has a negative relationship with number of dust storms occurring. Researching the contribution of soil moisture and daily mean wind speed to dust storms by means of comparing with the status in occurrence and non-occurrence of dust storms using the critical value of daily mean wind speed, a science basis should be set up for researching sand transit factors.

The changes in minimum daily mean wind speed and daily mean soil moisture under the two types was shown in Fig.2. Figure 2 (a) is the status of Type One in which dust storms occurred when daily wind speed was $\mathrm{V}>3.5 \mathrm{~m} / \mathrm{s}$. Figure 2 (b) is the status of Type Two in which non-occurrence of dust storms when daily wind speed also more than $V>3.5 \mathrm{~m} / \mathrm{s}$.

In Type one (Fig. 2(a)), daily mean wind speed are around $7.5 \mathrm{~m} / \mathrm{s}$ and more, daily mean soil moisture is $17.7 \%$, and there was a negative relationship between them of $(r=-0.674)$. When daily mean wind speed was stronger and appeared at a peak value, soil moisture was correspondingly weaker and represented the lowest value. The negative relationship is obvious in the figure. Namely, if the stronger wind speed combined with less soil moisture, the result of integrative action of both factors should accelerate the occurrence of dust storm.
Figure 2 (b) indicates the relationship between wind and soil moisture in the Type Two in which nooccurrence of dust storm when wind speed exceeds the critical wind speed. Compared with Fig 2(a), a status of occurrence of dust storm, the difference was not only that the average value of daily mean wind speed and daily mean soil moisture in Fig.2 (b) was changed to $5.5 \mathrm{~m} / \mathrm{s}$ and $19.0 \%$, this average value decreased $26.7 \%$ and $7.3 \%$ compared to Type One, respectively, but also that the negative relationship between daily mean wind speed daily mean soil moisture decreased from -0.674 of Type One to -0.026 of Type Two. According to a statistics test, $r=-0.026$ without passed test at a $p<0.05$ significant level, which indicates the negative relation between daily mean wind speed and disappeared daily mean soil moisture. If we consider the changing trend of both wind and soil moisture (solid line and broken line in Fig.2 (b)), they have the same changing trend instead of the negative relationship shown in Fig.2 (a). The positive relationship between daily mean wind speed and daily mean soil moisture shows that dust storm activity was controlled by the earth surface condition of wetter soil moisture under certain wind speed condition. Although daily mean wind speed exceeded the critical value of wind speed when dust storm occurred, if soil moisture increased to $19.0 \%$, dust storm would not occur in the study areas.
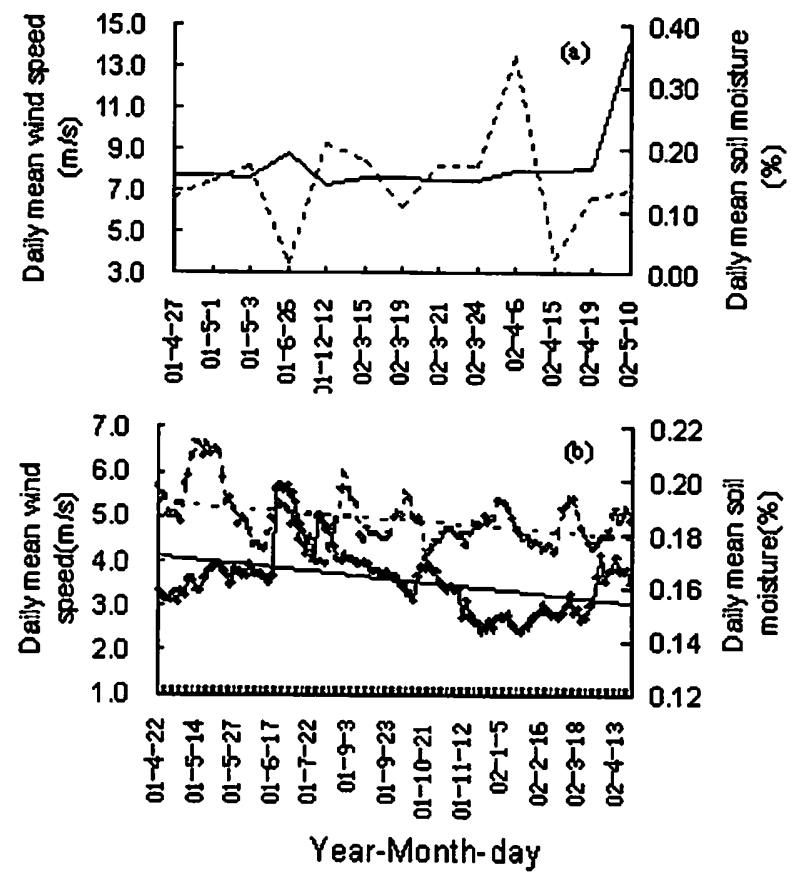

Fig. 2. Variation in soil moisture (\%) and daily mean wind speed $(\mathrm{m} / \mathrm{s})$ when the daily mean wind speed was above its critical value. (a): dust storm occurred, (b): no dust storm occurred, solid line represents soil moisture; broken line represents daily mean wind speed. 
The results in Type One and Type Two, in which negative correlation coefficient decreased from $r=$ 0.674 to $r=-0.026$, effectively confirms the contribution of soil moisture to dust storm activity. Because increasing soil moisture will increase the tension between water molecules and soil grain, the cohesive power in soil will intensify the soil's power to resist erosion. With respect to the increasing soil moisture, with the sand startup wind speed of soil grain increasing, the power to resist erosion increased. Wetter soil could. increase the requirement to blown sand up into the sky in the same location and same earth's surface condition.

\section{Results and Discussion}

With the ever growing population and their abusive use of land and water resources, human activities have an impact on enhancing the intensity of dust storm disasters and the interference of humans has become a triggering factor for the frequent occurrence of dust storms (Fan, et al., 2002). The studies on interaction mechanism between the formation, transition and sedimentation of dust storms and the characteristics of the earth's surface have been analyzed, but their integration to image the relation between condition of earth's surface and its soil moisture still have some limits because of the shortage of with soil moisture data corresponding to periods of dust storm occurrence. The statistical results are discussed using hourly soil moisture in the paper, from which some interesting results can be drawn as follows:

1) The critical value of daily mean wind speed for the occurrence of dust storm in the area is $3.5 \mathrm{~m} / \mathrm{s}$, dust storm certainly occur when daily mean wind speed is more than $8.0 \mathrm{~m} / \mathrm{s}$.

2) In terms of conditions with daily mean wind speed more than $3.5 \mathrm{~m} / \mathrm{s}$, in $18.4 \%$ of the entire whole data dust storm occurred, and in $81.6 \%$ of the whole data there was non-occurrence of dust storms. The results indicate that dust storm emission is an integrative action caused by multi factors. Gale weather representing dynamic factor should not be the most important factor for dust storm.

3) The form and development of dust storm disasters is an integrated outcome, in which the earth's surface is an important factor except the influence of strong wind and air circumfluence. Considering two factors of daily mean soil moisture and wind speed, if wind speed is above critical value, there is an obvious negative relationship between daily mean wind speed and daily mean soil moisture when dust storms occur. When the negative relationship disappears, dust storm will rarely occur.
The authors would like to thank Mr. Z. J. Li and X. $\mathrm{H}$. Wu for providing dust storm data of dust storm. This project was supported by the Ministry of Education of China.

\section{References}

Bai, J.Y., Shi, X.Y. and Yu, S Q., 2003: Preliminary Research on Soil Moisture in Eastern Part of Northwest China, Meteorological Science and Technology, 31 (4), 226-230.

Nilgun, K., and Slobodan, N., 2000: An illustration of the transport and deposition of mineral dist onto the eastern Mediterranean. Atmospheric Environment, 34, 1293-1303.

Shao, Y.P., 2000: Physics and Modeling of Wind Wrosion. Kluwer Academic Publishers, The Netherlands, pp. 135-136.

Gu, W., Cai, X.P., Xie, F. Li, Z.J. and Wu, X.H., 2002: Study on Relationship Between Vegetation Cover and Distribution of Days of Sandstorm-Taking central and western Inner Mongolia for example. Advance in Earth Sciences, 17 (2), 273-277.

Fan, Y. D., Shi, P. J., Wang, X. S. and Pan, Y. Z., 2002: The Analysis of Typical Dust Storm in Northern China by Remote Sensing, Advance in Earth Sciences, 17 (2), 289-294.

Acknowledgment 